\title{
Metabolic Imaging in the Study of Oncological Processes (Review)
}

\author{
DOI: $10.17691 / \mathrm{stm} 2016.8 .4 .16$ \\ Received November 9, 2015
}

M.M. Lukina, Junior Researcher, Laboratory of Studying Optical Structure of Biotissues,

Institute of Biomedical Technologies ${ }^{1}$; PhD Student, Department of Biophysics,

Institute of Biology and Biomedicine ${ }^{2}$;

M.V. Shirmanova, PhD, Head of the Laboratory of Individual Cancer Chemotherapy,

Institute of Biomedical Technologies";

T.F. Sergeeva, PhD, Researcher, Fluorescent Bioimaging Laboratory, Institute of Biomedical Technologies';

E.V. Zagaynova, MD, DSc, Director, Institute of Biomedical Technologies ${ }^{1}$

${ }^{1}$ Nizhny Novgorod State Medical Academy, 10/1 Minin and Pozharsky Square, Nizhny Novgorod, 603005,

Russian Federation;

${ }^{2}$ Lobachevsky State University of Nizhni Novgorod, 23 Prospekt Gagarina, Nizhny Novgorod, 603950, Russian Federation

There have been reviewed the main approaches to the study of energy metabolism in cancer cells, based on fluorescent imaging of NADH and FAD cofactors. The term "metabolic imaging" covers a range of modern fluorescent techniques for detecting NADH and FAD according to fluorescence intensity and/or lifetime. These cofactors play an important role in energy metabolism reactions acting as electron carriers and, being fluorescent, serve as a basis for metabolic process analysis in living cells and tissues without the use of additional coloring agents. Particular attention is paid to metabolic changes associated with carcinogenesis. Numerous examples of metabolic imaging application in cell cultures in vitro, animal and human tumors in vivo, as well as in patients' tumor biopsy samples have demonstrated its being highly demanded for biomedical research in the area of oncology.

Key words: metabolic imaging; energy metabolism; fluorescence lifetime; redox ratio; NADH; FAD; oxidative phosphorylation; glycolysis; tumor cells.

Cells need energy to maintain homeostasis. All processes of cell activity, such as generating concentration gradients, cytoskeleton movement, DNA repair, transcription, translation and vesicular transport, are energy-dependent. Energy metabolism of normal cells is known to differ significantly from cell metabolism in case of a disease. Therefore, the metabolic status can serve as an indicator for diagnosis and visualization of response to pathological process treatment. Taking into account high incidence of oncological diseases, assessment of metabolic phenotype of tumor cells is particularly urgent.

Development of optical visualization technologies has provided the possibility of noninvasive analysis of metabolic cofactors NADH and FAD in living tumor cells at high spatial resolution (up to several hundred nanometers) without using additional coloring agents and with no significant effect on biochemical and physiological condition of cells. The term "metabolic imaging" covers a range of modern fluorescent techniques which allow visualizing NADH and FAD according to their fluorescence intensity and/or lifetime.

The present review characterizes the properties of energy metabolism in cancer cells, describes the two key approaches to the assessment of metabolic status: analysis of cofactor fluorescence intensity ratio (redox ratio) and their fluorescence lifetime. There have been presented numerous examples of metabolic imaging application in cell cultures in vitro, animal and human tumors in vivo, as well as in patients' tumor biopsy samples.

For contacts: Mariya M. Lukina, e-mail: kuznetsova.m.m@yandex.ru 


\section{Cofactors NADN and FAD and their role in cellular energy metabolism}

The most important ways of cellular energy metabolism such as glycolysis and oxidative phosphorylation are related to cellular respiration and ATP synthesis. Cofactors NADH and FAD which are present in the cell in an oxidized $\left(\mathrm{NAD}^{+}, \mathrm{FAD}\right)$ or reduced form (NADN, $\left.\mathrm{FADN}_{2}\right)$ play the role of electron donors and acceptors in reactions of ATP formation [1-7].

In the process of glycolysis, the glucose molecule is decomposed into two pyruvate molecules, with two $\mathrm{NAD}^{+}$ molecules being reduced to two NADH molecules and two ATP molecules formed in reactions of substrate-level phosphorylation $[8,9]$ :

$$
\begin{aligned}
& \mathrm{C}_{6} \mathrm{H}_{12} \mathrm{O}_{6}+2 \mathrm{ADP}+2 \mathrm{H}_{3} \mathrm{PO}_{4}+2 \mathrm{NAD}^{+}= \\
& =2 \mathrm{C}_{3} \mathrm{H}_{4} \mathrm{O}_{3}+2 \mathrm{NADN}_{2}+2 \mathrm{ATP}+2 \mathrm{H}_{2} \mathrm{O} .
\end{aligned}
$$

Then the pyruvate molecule can be transported into the mitochondria where it is converted to acetyl coenzyme $A$ as a result of dehydrogenation and decarboxylation reactions. These reactions take place with help of multifermental pyruvate dehydrogenase complex consisting of three enzymes: pyruvatedecarboxylase, dehydrolipoyl transacetylase and dihydrolipoamide dehydrogenase ( $\mathrm{LipDH}$ ), as well as five coenzymes: thiamin diphosphate, lipoic acid, FAD, NAD ${ }^{+}$ and coenzyme A. Subsequently, acetyl coenzyme A joins Krebs cycle. Numerous dehydrogenase complexes in the mitochondria play an important role in regulation of $\mathrm{NAD}^{+} /$ $\mathrm{NADH}$ ratio and NADH pool which is a donor of electrons and protons for mitochondrial respiratory chain [10-13].

Oxidative phosphorylation is the most effective way of producing ATP, NADH is the primary donor and FAD is the primary electron and proton acceptor in mitochondrial respiratory chain. As a result of glycolysis and Krebs cycle reactions, one molecule degradation can lead to the production of $10 \mathrm{NADH}$ molecules. In the process of tissue respiration, electrons and protons are transported from NADH onto oxygen through the respiratory chain complexes, with $\mathrm{NADH}$ being oxidized to $\mathrm{NAD}^{+}$and protons moving from the mitochondrial matrix to the intermembrane space, which leads to generation of a proton gradient (electrochemical potential). The energy of electrochemical potential is used for ATP synthesis during the reverse transport of protons to the mitochondrial matrix by means of ATP synthase [14-16].

The overall diagram of NADH and FAD involvement in cellular energy metabolism reactions is as follows (Figure 1) [17].

Coenzymes NADH and FAD are able to fluoresce (Figure 2). NADH fluorescence excitation spectrum lies in the region of 300-400 nm with the peak wavelength of $355 \mathrm{~nm}$, emission spectrum is in the region of

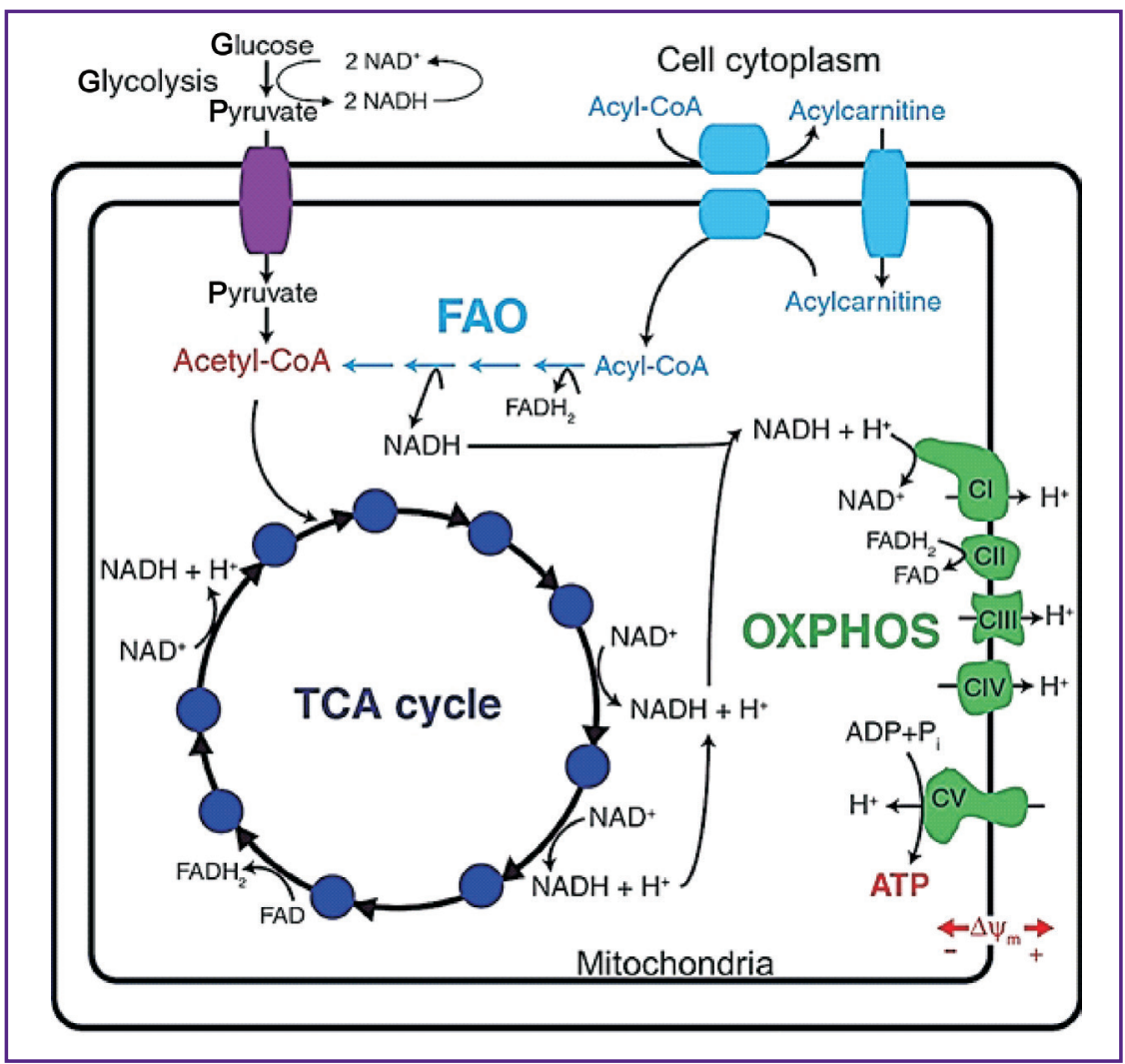

Figure 1. The diagram of metabolic cofactors NADH and FAD involvement in cellular energy metabolism [17] 


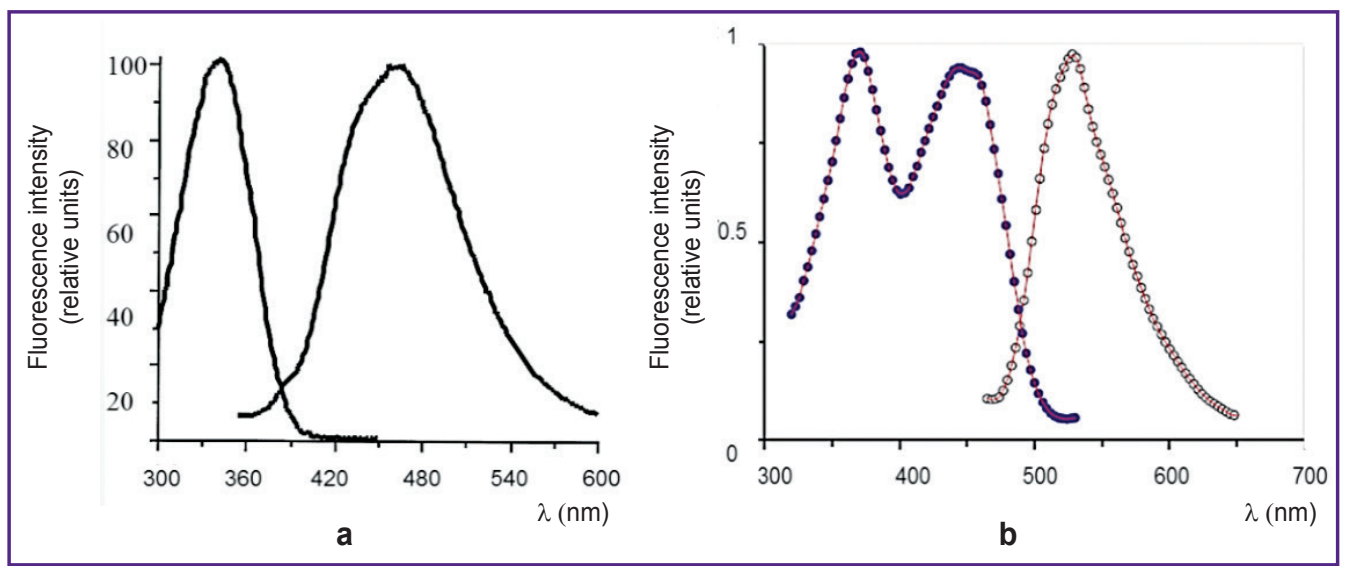

Figure 2. NADH (a) and FAD (b) absorption and fluorescence spectra

400-600 $\mathrm{nm}$ with the maximum at $\lambda=470 \mathrm{~nm}$. FAD fluorescence excitation spectrum is in the range of 350 $500 \mathrm{~nm}$ with two maximums at $370 \mathrm{~nm}$ and $450 \mathrm{~nm}$, emission spectrum is in the range of $500-600 \mathrm{~nm}$ with the maximum at $\lambda=525 \mathrm{~nm}[18-21]$.

Phosphorylated NADH (NADPH) has the same spectral properties as non-phosphorylated NADH, though it is not involved in energy metabolism reactions directly. The main NADPH source in the cell is pentose phosphate pathway (exclusive of the tissues where there is active synthesis of fatty acids and steroids and other reactions contribute to NADPH production). NADPH participates in biosynthesis of fatty acids, carotenoids and steroids. Besides, NADPH is of great importance to antioxidant systems, particularly, the glutathione-ascorbate cycle, and regulates the processes of passing cellular signals. Oxidized $\mathrm{NADP}^{+}$maintains $\mathrm{Ca}^{2+}$ homeostasis in the cell [4-7]. According to the data reported in a number of papers, NADPH concentration in the cell is dozens of times lower than that of $\mathrm{NADH}$, and fluorescence quantum yield is 1.25-2.5 times less [21-23]. As a rule, $\mathrm{NADPH}$ contribution is not taken into account in energy metabolism analysis.

$\mathrm{NADH}$ in the cell is in a free and protein-bound state. Free NADH is localized in cell cytosol and differs from the protein-bound form in emission spectrum (it is shifted $20 \mathrm{~nm}$ to the red). The main fluorescence in the blue range is emitted by protein-bound NADH localized in the mitochondria while the free form contribution is rather small [18], with protein-bound $\mathrm{NADH}$ quantum yield increasing nearly four times [20].

$F A D$ in the cell is bound with mitochondrial enzymes called flavoproteins. FAD fluorescence is quenched by most of these enzymes, including succinate dehydrogenase which is the key enzyme in tricarboxylic acid cycle and the second complex of mitochondrial respiratory chain. About $50 \%$ of FAD fluorescence is emitted by LipDH-containing enzyme complexes, 25\% by an electron carrier, flavoprotein, which serves as an intermediary accepting the electrons and protons from fatty acids during $\beta$-oxidation and transferring them to the ubiquinone pool. Though flavoproteins do not participate in glucose metabolism directly, they are capable of quenching FAD fluorescence when reductive-oxidative cell status changes $[10,11,24,25]$. The last $25 \%$ of FAD fluorescence is emitted by sodium dithionite and it is not related to metabolism [10]. The ratio of the bound FAD to $\mathrm{FADH}_{2}$ increases as the rate of Krebs cycle reactions grows and it decreases when the rate of NADH oxidation in mitochondrial electron transport chain is inhibited [26].

Understanding the role of $\mathrm{NADH}$ and FAD in metabolic cell reactions is of utter importance for appropriate interpretation of the data obtained by fluorescent analysis. NADH is localized mainly in the mitochondria and participates predominantly in cellular energy metabolism, while FAD is contained in both cytoplasm and mitochondria and is involved, apart from oxidative phosphorylation, in various biochemical processes (glutathione utilization, lipogenesis, lipid peroxidation, antioxidant reactions, acetyl coenzyme $A$ synthesis, the glutathione-ascorbate cycle, the pentose phosphate cycle), which considerably complicates data analysis [4, $13,21,27]$.

\section{Metabolic properties of tumor cells}

Tumor cells are characterized by active uncontrollable proliferation, therefore, their energy metabolism has certain specific features as compared to normal tissues. Unlike normal cells whose main way of ATP synthesis is oxidative phosphorylation, the majority of cancer cells have elevated glycolysis.

Hypoxia resulting from the imbalance between oxygen delivery and consumption in the tissue is characteristic of many solid tumors. Oxygen level in hypoxic tumors is considered to be lower than in healthy tissues, averaging $1-2 \%$ and less. The main factors of hypoxia development in the tumor are the atypical structure of microcirculatory vessels, long distances between blood vessels and tumor cells, which limits oxygen delivery with diffusion, and also 
low oxygen transport by blood due to anemia. Numerous investigations in the last two decades have shown that hypoxia plays a significant role in tumor progression and is an adverse factor for treatment prognosis [28-30]. Hypoxia induces many complicated signaling pathways, including HIF, PI3K/AKT/mTOR, MARK, NF-KB, involved in regulation of proliferation, apoptosis, inflammation, migration, survival and metabolism. Among them, HIF1 and $\mathrm{mTOR}$ play the most essential role in regulation of metabolism [31-33]. HIF1 transcription factor is the principal regulator of glucose metabolism in conditions of hypoxia. It can promote mitochondrial degradation through BNIP3-dependent autophagy and also block mitochondrial biosynthesis inhibiting the activity of MYC transcription factor. The mTOR pathway is involved in starting reactions of glycolysis, biosynthesis of lipids, amino acids, nucleotides and proteins. As a result, in conditions of low oxygenation, tumor cells are unable to trigger reactions of oxidative phosphorylation, which makes them pass to glycolysis [28, 34-36].

Tumor cells, unlike normal ones, use glycolysis even in normal oxygenation conditions. This effect was discovered by German physiologist, Otto Warburg, in 1920s and was called aerobic glycolysis, or the Warburg effect [37-39]. Warburg reckoned that prevalence of glycolysis in presence of oxygen was caused by irreversible impairment of mitochondrial functions. As it was found later, actually, only a few tumor lines have mitochondrial dysfunctions, such as decreased expression of protein carriers and enzymes participating in reductive-oxidative reactions, reduced cycle of tricarboxylic acids, low number of the mitochondria, structural impairment of the respiratory chain complex, increased number of mitochondrial ATP-synthase inhibitors and high mDNA sensitivity to oxidative stress. It was established that many tumor cells restored mitochondrial functions and passed to oxidative phosphorylation when glycolysis reactions were inhibited [40-44].

Tumor cells switching to glycolytic metabolism is caused by a number of reasons. Firstly, this occurs due to essential need of tumor cells for synthesis of macromolecules for active growth. It is glycolysis which results in forming monomers necessary for synthesis of nucleic acids, proteins and lipids. Secondly, production of free radicals is decreased in glycolysis, which reduces the level of genotoxic damages to the cell and helps avoid apoptosis [8, 26, 41, 45, 46]. Thirdly, the product of glycolysis is lactate which is transported to the intercellular space. Acidic media are known to promote the invasion of tumors and metastasis. Besides, high ATP concentration has adverse effect on tumor cells as it suppresses glycolysis inhibiting phosphofructokinase-1 and pyruvate kinase [40].

So far, it has been established that energy metabolism of tumor cells presents a balance between glycolysis and oxidative phosphorylation and the theory of "pure glycolysis" in the tumor has been disproved. Experiments with decreasing the oxygen level have shown that no tumor cell can exist only by means of glycolysis. A variety of gliomas, hepatomas and breast cancer cell lines use oxidative phosphorylation reactions as the main ATP source (though their metabolic phenotype changes in conditions of hypoxia). The maximum contribution of glycolysis to ATP production in tumor cells is considered to be no more than $50-60 \%$, and in certain cases the level of oxidative phosphorylation in tumor cells is even higher than in the surrounding stromal cells [9, $41,42,47]$. Besides, some tumor cells are capable of reversible switching between glycolysis and oxidative phosphorylation depending on glucose availability in the environment [9, 42]. Tumors as such are metabolically heterogenic and the ratio of ATP production by glycolysis and oxidative phosphorylation can vary significantly in different cells of the same tumor lesion [41, 48].

Thus, metabolic activity of tumor cells presents a complicated process that helps cancer cells to adjust to various environmental conditions and their changes [42, 49-51].

\section{Redox ratio as metabolic status indicator}

Principles and techniques for measuring redox ratio. Since NADH and FAD are the only electron carriers capable of fluorescence, the ratio of their fluorescence intensities may serve as a parameter for assessment of the metabolic status of cells and tissues. The ratio of oxidized electron carriers to reduced ones is called redox ratio. This approach was suggested by Chance et al. [26, 52]. In literature there are various options for calculating redox ratio:

$$
\begin{aligned}
& \text { FAD/(NADH+FAD) [53-56]; } \\
& \text { FAD/NADH [22, 57-60]; } \\
& \text { NADH/FAD [61-63]. }
\end{aligned}
$$

The choice of formula for calculating redox ratio often depends on the ratio of cofactor fluorescence intensities, the type of subject under study and measurement method $[63,64]$.

Since NADH is largely formed during glycolysis and FAD during oxidative phosphorylation, low redox ratio indicates high metabolic activity of cells and prevalence of the glycolytic pathway over oxidative phosphorylation. In addition to increasing glycolysis, active Krebs cycle reactions take place in proliferating tumor cells, with a possibility of its intermediate products being removed from the cycle for synthesis of various compounds. Increase in glycolysis and/or Krebs cycle, as compared to oxidative phosphorylation, leads to NADH accumulation. If NADH fluorescence intensity is increased, the cell has high metabolic potential for ATP production by means of oxidative phosphorylation reactions. Increase in NADH concentration is characteristic of tumor cells $[65,66]$.

Decrease in NADH fluorescence intensity and increase in FAD (high redox ratio) shows substantial need for ATP and oxidative phosphorylation predominance. For the healthy cell in standard conditions with the optimum 
nutrient and oxygen content, increased need for ATP leads to the growth of redox ratio. It is caused by NADH oxidation to $\mathrm{NAD}^{+}$during oxidative phosphorylation. In conditions of hypoxia with lack of oxygen serving as the final electron acceptor in mitochondrial respiratory chain, oxidative phosphorylation reactions become impossible and NADH concentration increases. To meet the need for ATP, the cell switches to anaerobic glycolysis resulting in $\mathrm{NAD}^{+}$being reduced to NADH with pyruvate and ATP formation. Lack of NADH oxidation through the electron transport chain and increase in NADH concentration resulting from glycolysis lead to NADH fluorescence intensity growth in the cell with hypoxia [26, 52, 67].

To measure NADH and FAD fluorescence, fluorescence imaging techniques with one- and twophoton excitation are used [26, 56].

With one-photon mode NADH excitation is performed at $350 \mathrm{~nm}$ with reception range at $450-470 \mathrm{~nm}$. FAD fluorescence is usually excited at $\lambda=450 \mathrm{~nm}$ and recorded in the range of $500-550 \mathrm{~nm}[18,20,26,52]$. Studies using one-photon mode are generally limited to in vitro models due to considerable light scattering in thick tissue samples [26].

Evaluation of metabolic status using two-photon fluorescence microscopy has a number of advantages compared to one-photon mode. In two-photon excitation the molecule of fluorophore absorbs two low-energy photons during one quantum event. As a result, it is possible to excite NADH and FAD fluorescence in the IR area (NADH in the region of $740 \mathrm{~nm}$ and FAD in the region of $900 \mathrm{~nm}$ ), but not in the UV and near UV range $[18,26]$. It is particularly significant for in vivo studies as light scattering in the tissue decreases when fluorescence is excited in the IR area. Besides, since simultaneous absorption of two photons has a probabilistic nature, effective two-photon excitation occurs only in the focal area where photon density is the highest. Such focused fluorescence excitation reduces the possibility of sample damage and photo-decolorization [26].

Redox ratio in tumor cells and tissues. Currently, redox ratio indicator is used for evaluation of metabolic status of tumor cells in vitro, tissue ex vivo and tumors in vivo. Ostrander et al. [62] showed on various human breast cancer cell cultures that tumor cells had increased NADH/FAD redox ratio compared to normal epithelial cells. This was related to elevated glucose consumption and aerobic glycolysis in tumor cells. Besides, subpopulation of breast cancer cells expressing estrogen receptors was reported to have decreased redox ratio. Similar results were also demonstrated on human bladder cancer cell line: NADH/FAD redox ratio was increased as compared to the norm [68].

It was revealed on breast cancer cell lines MDAMB-231, MCF7, SKBr3 and BT474 that NADH/FAD redox ratio decreased after adding oxidative phosphorylation inhibitor FCCP, which spoke of metabolic changes in cells [69]. There was found a direct correlation between FAD/ $(\mathrm{NADH}+\mathrm{FAD})$ redox ratio and oxygen consumption on various cultures of human breast cancer cells in vitro [70]. Besides, the interrelation between NADH/FAD redox ratio and $H E R 2$ gene expression was demonstrated on human breast cancer cell culture. HER2 is known to play an important role in pathogenesis and progression of certain aggressive types of breast cancer. It has been established that the highest NADH/FAD redox ratio is characteristic of cells with over-expression of HER2 [71, 72].

Levitt et al. studied metabolic activity of normal and pre-cancer HPV-immortalized cells on a 3D model of epithelium. Pre-cancer cells were found to have decreased $\mathrm{FAD} /(\mathrm{NADH}+\mathrm{FAD})$ redox ratio as compared to normal cells due to glycolysis prevalence $[53,73]$. The study of changes in FAD/NADH redox ratio in human uterine neck cancer cells in conditions of co-cultivation with fibroblasts [57] revealed that redox ratio in tumor cells decreased in co-cultivation with fibroblasts. This decrease was caused by transition to more glycolytic metabolism. It was demonstrated on oral cancer cells (SCC25 and SCC61) in vitro that NADH/FAD redox ratio decreased after treatment of cells with Cisplatin [74]. Similar results were obtained on bladder cancer cell line (T24). After administration of N-4(hydroxyphenyl)-retinamide there was observed increase in FAD/(NADH+FAD) redox ratio [75].

The study of metabolic changes in mucous membrane epithelium of hamster cheek pouch in vivo demonstrated decrease in FAD/NADH redox ratio in carcinogenesis [60]. The works [76-78] showed on the same model that $\mathrm{FAD} /(\mathrm{NADH}+\mathrm{FAD})$ redox ratio decreased sharply in tumor tissue as compared to the control, which indicated its increased metabolic activity. In the works $[60,78]$ there was revealed $F A D /(N A D H+F A D)$ redox ratio difference between metastasizing breast cancer cell line MDA-MB231 and non-metastasizing MCF7 in vivo. Redox ratio in MDAMB231 cells was higher, which the authors attribute to more aggressive phenotype of the metastasizing line.

Some works are devoted to the study of metabolic changes in anticancer therapy in vivo. For example, A.T. Shah et al. have observed statistically significant decrease in FAD/NADH redox ratio of laryngeal squamous cell carcinoma ( $\mathrm{FaDu}$ ) in vivo on the second day of chemotherapy with Cisplatin [79]. Zhang et al. describe increase in $F A D /(N A D H+F A D)$ redox ratio in rat glioma cells in vivo after photodynamic therapy (PDT) [56]. In the work [80] they show sharp increase in FAD/ (NADH+FAD) redox ratio in rat glioma cells after PDT ex vivo due to oxidative stress initiation and mitochondrial structure impairment.

This method (using redox ratio for assessment of the metabolic status of tumor cells) is applied for clinical research as well. Natal et al. have analyzed biopsy material from patients with breast tumor [54]. FAD/NADH redox ratio was found to be decreased in samples from patients with desmoplastic reaction, which indicated high metabolic activity of these cells and unfavorable prognosis. Shah and Skala have proved the possibility of using NADH/FAD redox ratio for the analysis of biopsy material from patients with malignant neoplasms of the 
larynx, the tongue, the epidermis and salivary gland adenocarcinoma ex vivo. The data obtained by them suggest that the metabolic status of tumor cells can serve as a criterion for selecting adequate treatment [81]. It was shown on uterine neck epithelium samples that samples with dysplasia had decreased FAD/(NADH+FAD) redox ratio compared to normal epithelium [82]. Similar results were obtained on rat brain tumor ex vivo: FAD/ (NADH+FAD) redox ratio in the tumor was much lower than in the normal tissue, which suggested prevalence of glycolysis in tumor cells [83]. Supposedly, the difference in redox ratio values may be used for visualization of tumor boundaries during the operation [83].

Though we have found no clinical examples of redox ratio recording, the analysis of metabolic cofactor fluorescence intensity has high potential for use in a clinical setting. A number of works show the results of recording NADH fluorescence in tumors of patients. Increased NADH fluorescence intensity is reported to indicate dysplastic and oncological changes of human uterine neck tissue epithelium in vivo [84]. Increased $\mathrm{NADH}$ fluorescence intensity, as compared to normal epithelium, has also been revealed in human head and neck tumors in vivo [85]. Similar results have also been obtained when studying human basal cell carcinoma in vivo [3]. All authors attribute high NADH fluorescence intensity to active metabolic processes in tumor cells.

\section{NADH and FAD fluorescence lifetime in energy metabolism evaluation}

Fluorescence lifetime imaging. Studying cellular metabolism by fluorescence lifetime imaging (FLIM) is based on the fact that fluorescence lifetime of cofactors $\mathrm{NADH}$ and FAD significantly differs depending on whether they are in a free or protein-bound state. Despite the large number of works devoted to studying cellular metabolic status based on redox ratio measurement, spectral separation of free and bound cofactor forms is impossible with this approach as their emission spectra differ by 10 $20 \mathrm{~nm}$ at the peak width of $150 \mathrm{~nm}[18,86]$.

FLIM provides the possibility to study metabolic cofactors in living cells by measuring mean time spent by the molecule in an excited state and not factual fluorescence intensity. Fluorescence lifetime does not depend on the fluorophore concentration, while the microenvironment is the most significant factor. Lifetime can be affected by $\mathrm{pH}$, temperature, concentration of ions and oxygen, binding to other molecules or the chromophore conformation [87, 88].

FLIM methodology for distinguishing free and bound NADH was proposed by Lakowicz et al. in 1992 [89]. For the first time they have measured NADH lifetime when free in solution ( $0.4 \mathrm{~ns})$ and when bound to malate dehydrogenase (1 ns). Recently, Blacker et al. have developed a technique for distinguishing NADH and NADPH fluorescence in living cells and tissues using FLIM [21].
At present the main approach to measuring fluorescence lifetime is time-correlated single photon counting (TCSPC). Fluorescence decay kinetics is measured after the sample excitation with short-pulse laser radiation (femto- and picosecond). Decay profile consists of multiple repetition of a single photon event. The time the first photon arrives on the detector after excitation pulse is measured and stored in the memory so that the histogram of photon times and arrivals presents a curve of fluorescence intensity in terms of time [90-92] (Figure 3). Since the measurement data require time resolution of a few seconds, FLIM systems are equipped with high-speed supersensitive detectors capable of detecting single photons [93, 94].

The specific cofactor fluorescence lifetime in the cell amounts to nearly 0.3 and 0.2 ns for $\mathrm{NADH}, 0.3$ and 2.7 ns for FAD. A shorter lifetime corresponds to bound FAD and free $N A D H$, a longer lifetime signals free $F A D$ and bound NADH.

Though in case of FAD the different lifetime is caused not by protein-binding, but the cofactor molecule conformation inside the protein compound, the use of terms "free" and "bound" for FAD is rather traditional. FAD is known to exist in two conformations: closed, when aromatic rings of isoalloxazine and adenine are in extremely close proximity, and open conformation, in which the two aromatic rings are extremely separated from each other. In open conformation, emission is carried out by means of aromatic group of isoalloxazine and the lifetime is about 2-3 ns, while closed conformation fluorescence lifetime is much shorter (100-300 ns) because isoalloxazine fluorescence is quenched by adenine $[21,57,86]$.

Free NADH is localized in the cytosol and is responsible for glycolysis processes, while its bound form is in mitochondria and participates in oxidative phosphorylation reactions. Bound NADH lifetime depends on the protein the cofactor is bound to and varies within 1.7 to 2.9 ns $[26,60,95]$.

There are a number of works devoted to the analysis of cofactor lifetime changes in oncological processes, yet the main indicator in studying energy metabolism by FLIM method is relative percentage contribution of free and bound cofactors [22, 26, 57, 95].

Today, fluorescence lifetime imaging is carried out as two-photon excitation microscopy, spectroscopy and macro imaging. There is equipment for two-photon microscopy and FLIM, approved for application in clinic, such as MPTflex and Dermalnspect systems produced by JenLab (Germany) [3, 96, 97].

Fluorescence lifetime changes in oncological processes. Due to noninvasiveness, high sensitivity and no need to introduce exogenous dyes, FLIM method has become an indispensable tool for tumor metabolism visualization.

Many works report that FLIM helps to demonstrate more glycolytic metabolism of tumor cells as compared to healthy ones. For example, decreased percentage 


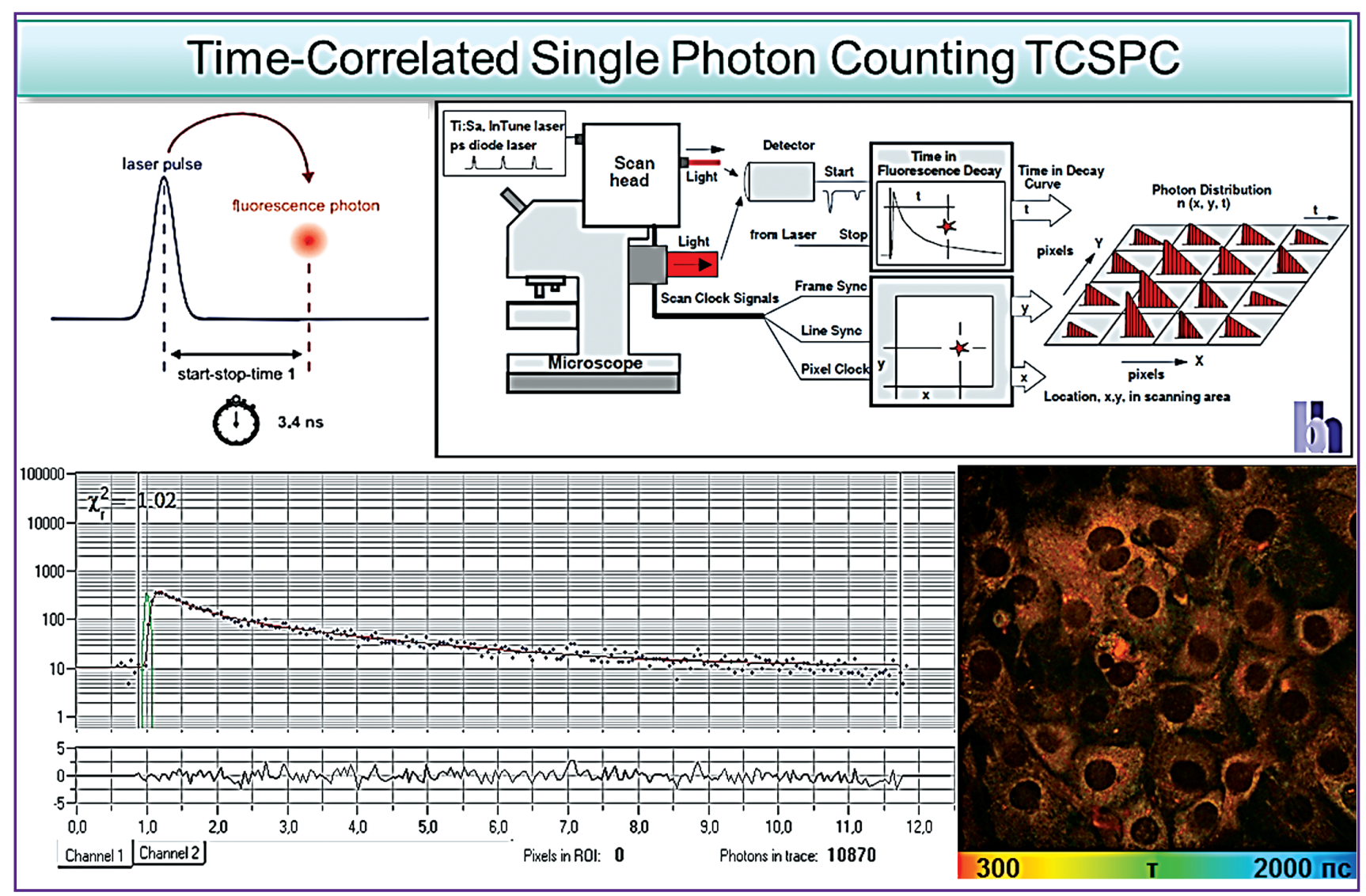

Figure 3. The working principle of time-correlated single photon counting method [1, 93]

contribution of bound $\mathrm{NADH}$ and FAD, as compared to normal epithelial cells, was revealed on head and neck cancer cell cultures SCC25 and SCC61 [74]. The same work demonstrates increased contribution of bound $\mathrm{NADH}$ and FAD after treatment with chemotherapeutic agents Cisplatin, Cetuximab and BGT226. The study of NADH lifetime in keratinocytes and human oral cavity tumor cells revealed in vitro that tumor cells had longer $\mathrm{NADH}$ fluorescence lifetime and the ratio of their free and bound $\mathrm{NADH}$ was reduced as compared to control [98]. Besides, it was found that NADH fluorescence lifetime in human breast cancer cells was significantly lower compared to normal epithelial cells [86]. Ramanujan et al. measured specific NADH fluorescence lifetimes for human embryonic kidney cells (HEK 293T), hepatocytes and human uterine neck cancer cell line (HeLa) and proved free NADH contribution to be the highest in tumor cells, which spoke of cellular metabolism shifting to glycolytic mode [99]. NADH fluorescence lifetime was analyzed on rat cell cultures of basophilic leukemia in normal conditions and when changing glucose concentration [100]. It was found that the lowest mean NADH lifetime value correlated with decreased glucose content and cell starvation. Mean NADH lifetime increased as glucose concentration increased in the environment. It was established on human breast cancer cell cultures that bound NADH fluorescence lifetime decreased in the process of cell proliferation and percentage contribution of its free form increased. The same changes, but with different dynamics, were observed when adding potassium cyanide to the cells and when decreasing the concentration of nutrients in culture medium [101].

Islam et al. has found FAD fluorescence lifetime to change in human uterine neck cancer cells with the change of $\mathrm{pH}$. Fluorescence lifetime remained unchanged with the change of extracellular $\mathrm{pH}$, however, with alkalization of intracellular $\mathrm{pH}$ it decreased [102].

The work [103] studies fluorescence distribution of flavins, their specific lifetime and contribution to metabolic processes on human glioblastoma tumor cells U-87 MG in vitro. It has been revealed that in tumor cells flavins are mostly localized in the mitochondria and mean FAD lifetime is $1.4 \mathrm{~ns}$. This fact can serve as a criterion for early diagnosis of oncological processes.

It was demonstrated in vivo that percentage contribution of bound NADH and FAD decreased in the process of carcinogenesis in the hamster cheek pouch epithelium cells as a result of glycolysis activation [60, 95]. The same model of induced oral cavity cancer was used by Fatakdawala et al. to show decreased NADH fluorescence lifetime in the tumor compared to the norm [104]. There was found decrease in $\mathrm{NADH}$ and 
FAD fluorescence lifetime as a result of chemotherapy with Cisplatin and Cetuximab on the cells of laryngeal squamous cell carcinoma ( $\mathrm{FaDu})$ in vivo [79].

Recently, application of FLIM method in clinical oncology has presented particular interest. Analysis of cofactors in human tumors is performed mainly on biopsy samples. Tumor samples from patients with larynx, tongue, epidermis cancer and salivary gland adenocarcinoma have been used to analyze NADH and FAD lifetime ex vivo [81]. This investigation shows that oncological processes have their specific metabolic properties and differ from the norm by more glycolytic metabolism. The study [54] revealed on breast cancer samples ex vivo that tumor cells with desmoplastic reaction had shorter NADH and FAD fluorescence lifetime as compared to tumor cells without this reaction. In human ovarian tumor samples ex vivo there was found increased FAD fluorescence lifetime as compared to normal epidermis [105].

It has been established using FLIM macro-imaging on biopsy samples that basalioma cells have shorter NADH fluorescence lifetime as compared to the norm [106]. It has been demonstrated on the samples of tumor of intestine, stomach, bladder, liver and pancreas that mean $\mathrm{NADH}$ fluorescence lifetime is significantly longer as compared to its value on the border between the tumor and healthy tissue of the same sample [107].

Due to small probing depth $(\sim 300 \mu \mathrm{m})$, FLIM-using procedures on human tumors in vivo are limited to the analysis of skin and brain (intraoperatively) neoplasms. Thus, NADH lifetime has proved to be considerably shorter in melanoma cells than in those of basalioma and this can serve as a criterion for differential diagnosis [97]. The first study has shown FLIM applicability for evaluating resection borders during neurosurgical intervention on brain tumor in vivo [96]. FLIM spectroscopy has been used in patients with head and neck tumors to reveal that tumor tissue cells have shorter NADH fluorescence lifetime as compared to the surrounding healthy tissue [108-110], which suggests their glycolytic status.

Conclusion. The data on the metabolic status of cells are important for evaluation of their functional state. All the examples given above demonstrate the potential of noninvasive optical methods for visualizing the metabolic status of tumor cells according to fluorescence of endogenic fluorophores NADH and FAD. The described approaches based on the analysis of fluorescence intensity (redox ratio) and fluorescence lifetime (FLIM) provide the possibilities for early diagnosis of oncological diseases and real-time monitoring the response to therapy. Metabolic imaging is expected to improve understanding dynamic biochemical processes in cells and to become the foundation for early diagnosis of not only oncological processes, but also other pathologies related to metabolic changes (diabetes mellitus, neurodegenerative diseases etc.).

Study Funding. This study was funded by the Russian Science Foundation (grant No.14-15-00646).
Conflicts of Interest. The authors have no conflicts of interest to disclose.

\section{References}

1. Chakraborty S., Nian F.-S., Tsai J.-W., Karmenyan A., Chiou A. Quantification of the metabolic state in cell-model of Parkinson's disease by fluorescence lifetime imaging microscopy. Sci Rep 2016; 6: 19145, https://doi.org/10.1038/ srep19145.

2. Folmes C.D., Dzeja P.P., Nelson T.J., Terzic A. Metabolic plasticity in stem cell homeostasis and differentiation. Cell Stem Cell 2012; 11(5): 596-606, https://doi.org/10.1016/j. stem.2012.10.002.

3. Balu M., Zachary C.B., Harris R.M., Krasieva T.B., König K., Tromberg B.J., Kelly K.M. In vivo multiphoton microscopy of basal cell carcinoma. JAMA Dermatol 2015; 151(10): 1068-1074, https://doi.org/10.1001/ jamadermatol.2015.0453.

4. Corpas F.J., Barroso J.B. NADPH-generating dehydrogenases: their role in the mechanism of protection against nitro-oxidative stress induced by adverse environmental conditions. Front Environ Sci 2014; 2, https:// doi.org/10.3389/fenvs.2014.00055.

5. Heikal A.A. Intracellular coenzymes as natural biomarkers for metabolic activities and mitochondrial anomalies. Biomark Med 2010; 4(2): 241-263, https://doi. org/10.2217/bmm.10.1.

6. Shi F., Li Y., Li Y., Wang X. Molecular properties, functions, and potential applications of NAD kinases. Acta Biochim Biophys Sin (Shanghai) 2009; 41(5): 352-361, https:// doi.org/10.1093/abbs/gmp029.

7. Xia W., Wang Z., Wang Q., Han J., Zhao C., Hong Y., Zeng L., Tang L., Ying W. Roles of $\mathrm{NAD}(+) / \mathrm{NADH}$ and NADP(+)/NADPH in cell death. Curr Pharm Des 2009; 15(1): 12-19, https://doi.org/10.2174/138161209787185832.

8. Cairns R.A., Harris I.S., Mak T.W. Regulation of cancer cell metabolism. Nat Rev Cancer 2011; 11(2): 85-95, https:// doi.org/10.1038/nrc2981.

9. Cantor J.R., Sabatini D.M. Cancer cell metabolism: one hallmark, many faces. Cancer Discov 2012; 2(10): 881-898, https://doi.org/10.1158/2159-8290.cd-12-0345.

10. Kunz W.S., Kunz W. Contribution of different enzymes to flavoprotein fluorescence of isolated rat liver mitochondria. Biochim Biophys Acta 1985; 841(3): 237-246, https://doi. org/10.1016/0304-4165(85)90064-9.

11. Saks V.A., Veksler V.I., Kuznetsov A.V., Kay L., Sikk P., Tiivel T., Tranqui L., Olivares J., Winkler K., Wiedemann F., Kunz W.S. Permeabilized cell and skinned fiber techniques in studies of mitochondrial function in vivo. In: Bioenergetics of the cell: quantitative aspects. Springer Science + Business Media; 1998; p. 81-100, https://doi.org/10.1007/978-1-46155653-4_7.

12. Pollak N., Dölle C., Ziegler M. The power to reduce: pyridine nucleotides - small molecules with a multitude of functions. Biochem J 2007; 402(2): 205-218, https://doi. org/10.1042/bj20061638.

13. Ying $W$. NAD+/NADH and NADP+/NADPH in cellular functions and cell death: regulation and biological consequences. Antioxid Redox Signal 2007; 10(2): 179-206, https://doi.org/10.1089/ars.2007.1672.

14. Smeitink J., van den Heuvel L., DiMauro S. The genetics and pathology of oxidative phosphorylation. Nat 
Rev Gene 2001; 2(5): 342-352, https://doi.org/10.1038/ 35072063.

15. Papa S., Martino P.L., Capitanio G., Gaballo A., De Rasmo D., Signorile A., Petruzzella V. The oxidative phosphorylation system in mammalian mitochondria. Adv Exp Med Biol 2012; 942: 3-37, https://doi.org/10.1007/978-94-0072869-1_1.

16. Gautheron D.C. Mitochondrial oxidative phosphorylation and respiratory chain: review. J Inherit Metab Dis 1984; 7(Suppl 1): 57-61, https://doi.org/10.1007/bf03047376.

17. Nsiah-Sefaa A., McKenzie M. Combined defects in oxidative phosphorylation and fatty acid $\beta$-oxidation in mitochondrial disease. Biosci Rep 2016; 36(2): e00313, https:// doi.org/10.1042/BSR20150295.

18. Chorvat D., Chorvatova A. Multi-wavelength fluorescence lifetime spectroscopy: a new approach to the study of endogenous fluorescence in living cells and tissues. Laser Phys Lett 2009; 6(3): 175-193, https://doi.org/10.1002/ lapl.200810132.

19. Patterson G.H., Knobel S.M., Arkhammar P., Thastrup O., Piston D.W. Separation of the glucose-stimulated cytoplasmic and mitochondrial $\mathrm{NAD}(\mathrm{P}) \mathrm{H}$ responses in pancreatic islet beta cells. Proc Natl Acad Sci USA 2000; 97(10): 5203-5207, https://doi.org/10.1073/pnas.090098797.

20. Richards-Kortum R., Sevick-Muraca E. Quantitative optical spectroscopy for tissue diagnosis. Annu Rev Phys Chem 1996; 47: 555-606, https://doi.org/10.1146/annurev. physchem.47.1.555.

21. Blacker T.S., Mann Z.F., Gale J.E., Ziegler M., Bain A.J., Szabadkai G., Duchen M.R. Separating NADH and NADPH fluorescence in live cells and tissues using FLIM. Nat Commun 2014; 5: 3936, https://doi.org/10.1038/ncomms4936.

22. Meleshina A.V., Dudenkova V.V., Shirmanova M.V., Shcheslavskiy V.I., Becker W., Bystrova A.S., Cherkasova E.I., Zagaynova E.V. Probing metabolic states of differentiating stem cells using two-photon FLIM. Sci Rep 2016; 6: 21853, https://doi.org/10.1038/srep21853.

23. Klaidman L.K., Leung A.C., Adams J.D. Jr. Highperformance liquid chromatography analysis of oxidized and reduced pyridine dinucleotides in specific brain regions. Anal Biochem 1995; 228(2): 312-317, https://doi.org/10.1006/ abio.1995.1356.

24. Huang S., Heikal A.A., Webb W.W. Two-photon fluorescence spectroscopy and microscopy of $\mathrm{NAD}(\mathrm{P}) \mathrm{H}$ and flavoprotein. Biophys J 2002; 82(5): 2811-2825, https://doi. org/10.1016/s0006-3495(02)75621-x.

25. Rocheleau J.V., Head W.S., Piston D.W. Quantitative $\mathrm{NAD}(\mathrm{P}) \mathrm{H} /$ flavoprotein autofluorescence imaging reveals metabolic mechanisms of pancreatic islet pyruvate response. J Biol Chem 2004; 279(30): 31780-31787, https://doi. org/10.1074/jbc.m314005200.

26. Georgakoudi I., Quinn K.P. Optical imaging using endogenous contrast to assess metabolic state. Annu Rev Biomed Eng 2012; 14: 351-367, https://doi.org/10.1146/ annurev-bioeng-071811-150108.

27. Kim H.J., Winge D.R. Emerging concepts in the flavinylation of succinate dehydrogenase. Biochim Biophys Acta 2013; 1827(5): 627-636, https://doi.org/10.1016/j. bbabio.2013.01.012.

28. Wouters B.G., Koritzinsky M. Hypoxia signalling through $\mathrm{mTOR}$ and the unfolded protein response in cancer. Nat Rev Cancer 2008; 8(11): 851-864, https://doi.org/10.1038/nrc2501.

29. Marusyk A., Polyak K. Tumor heterogeneity: causes and consequences. Biochim Biophys Acta 2010; 1805(1): 105117, https://doi.org/10.1016/j.bbcan.2009.11.002.

30. DeBerardinis R.J., Lum J.J., Hatzivassiliou G., Thompson C.B. The biology of cancer: metabolic reprogramming fuels cell growth and proliferation. Cell Metab 2008; 7(1): 11-20, https://doi.org/10.1016/j.cmet.2007.10.002.

31. Edinger A.L., Linardic C.M., Chiang G.G., Thompson C.B., Abraham R.T. Differential effects of rapamycin on mammalian target of rapamycin signaling functions in mammalian cells. Cancer Res 2003; 63(23): 8451-8460.

32. Peng T., Golub T.R., Sabatini D.M. The immunosuppressant rapamycin mimics a starvation-like signal distinct from amino acid and glucose deprivation. $\mathrm{Mol}$ Cell Biol 2002; 22(15): 5575-5584, https://doi.org/10.1128/ mcb.22.15.5575-5584.2002.

33. Masson N., Ratcliffe P.J. Hypoxia signaling pathways in cancer metabolism: the importance of co-selecting interconnected physiological pathways. Cancer Metab 2014; 2(1): 3, https://doi.org/10.1186/2049-3002-2-3.

34. Solaini G., Baracca A., Lenaz G., Sgarbi G. Hypoxia and mitochondrial oxidative metabolism. Biochim Biophys Acta 2010; 1797(6-7): 1171-1177, https://doi.org/10.1016/j. bbabio.2010.02.011.

35. Zhang H., Bosch-Marce M., Shimoda L.A., Tan Y.S., Baek J.H., Wesley J.B., Gonzalez F.J., Semenza G.L. Mitochondrial autophagy is an HIF-1-dependent adaptive metabolic response to hypoxia. J Biol Chem 2008; 283(16): 10892-10903, https://doi.org/10.1074/jbc.M800102200.

36. Zhang H., Gao P., Fukuda R., Kumar G., Krishnamachary B., Zeller K.I., Dang C.V., Semenza G.L. HIF-1 inhibits mitochondrial biogenesis and cellular respiration in VHL-deficient renal cell carcinoma by repression of C-MYC activity. Cancer Cell 2007; 11(5): 407-420, https://doi. org/10.1016/j.ccr.2007.04.001.

37. Lopez-Lazaro M. The warburg effect: why and how do cancer cells activate glycolysis in the presence of oxygen? Anticancer Agents Med Chem 2008; 8(3): 305-312, https://doi. org/10.2174/187152008783961932.

38. Warburg O., Wind F., Negelein E. The metabolism of tumors in the body. J Gen Physiol 1927; 8(6): 519-530, https:// doi.org/10.1085/jgp.8.6.519.

39. Pelicano H., Martin D.S., Xu R.H., Huang P. Glycolysis inhibition for anticancer treatment. Oncogene 2006; 25(34): 4633-4646, https://doi.org/10.1038/sj.onc.1209597.

40. Zheng J. Energy metabolism of cancer: glycolysis versus oxidative phosphorylation (review). Oncol Lett 2012; 4(6): 1151-1157, https://doi.org/10.3892/ol.2012.928.

41. Berridge M.V., Herst P.M., Tan A.S. Metabolic flexibility and cell hierarchy in metastatic cancer. Mitochondrion 2010; 10(6): 584-588, https://doi.org/10.1016/j.mito.2010.08.002.

42. Diaz-Ruiz R., Rigoulet M., Devin A. The Warburg and Crabtree effects: on the origin of cancer cell energy metabolism and of yeast glucose repression. Biochim Biophys Acta 2011; 1807(6): 568-576, https://doi.org/10.1016/j. bbabio.2010.08.010.

43. Fantin V.R., St-Pierre J., Leder P. Attenuation of LDH-A expression uncovers a link between glycolysis, mitochondrial physiology, and tumor maintenance. Cancer Cell 2006; 9(6): 425-434, https://doi.org/10.1016/j.ccr.2006.04.023.

44. Moreno-Sánchez R., Rodríguez-Enríquez S., MarínHernández A., Saavedra E. Energy metabolism in tumor cells. FEBS J 2007; 274(6): 1393-1418, https://doi.org/10.1111/ j.1742-4658.2007.05686.x. 
45. Brand K.A., Hermfisse U. Aerobic glycolysis by proliferating cells: a protective strategy against reactive oxygen species. Faseb J 1997; 11(5): 388-395.

46. Lunt S.Y., Vander Heiden M.G. Aerobic glycolysis: meeting the metabolic requirements of cell proliferation. Annu Rev Cell Dev Biol 2011; 27: 441-464, https://doi.org/10.1146/ annurev-cellbio-092910-154237.

47. Fogal V., Richardson A.D., Karmali P.P., Scheffler I.E., Smith J.W., Ruoslahti E. Mitochondrial p32 protein is a critical regulator of tumor metabolism via maintenance of oxidative phosphorylation. Mol Cell Biol 2010; 30(6): 1303-1318, https:// doi.org/10.1128/MCB.01101-09.

48. Zu X.L., Guppy M. Cancer metabolism: facts, fantasy, and fiction. Biochem Biophys Res Commu 2004; 313(3): 459465, https://doi.org/10.1016/j.bbrc.2003.11.136.

49. Robertson-Tessi M., Gillies R.J., Gatenby R.A., Anderson A.R. Impact of metabolic heterogeneity on tumor growth, invasion, and treatment outcomes. Cancer Res 2015; 75(8): 1567-1579, https://doi.org/10.1158/0008-5472.CAN-141428.

50. Sengupta D., Pratx G. Imaging metabolic heterogeneity in cancer. Mol Cancer 2016; 15: 4, https://doi.org/10.1186/ s12943-015-0481-3.

51. Xu H.N., Feng M., Moon L., Dolloff N., ElDeiry W., Li L.Z. Redox imaging of the p53-dependent mitochondrial redox state in colon cancer ex vivo. J Innov Opt Health Sci 2013; 6(3): 1350016, https://doi.org/10.1142/ s1793545813500168.

52. Chance B., Schoener B., Oshino R., Itshak F., Nakase Y. Oxidation-reduction ratio studies of mitochondria in freeze-trapped samples. NADH and flavoprotein fluorescence signals. J Biol Chem 1979; 254(11): 4764-4771.

53. Levitt J.M., Baldwin A., Papadakis A., Puri S., Xylas J., Munger K., Georgakoudi I. Intrinsic fluorescence and redox changes associated with apoptosis of primary human epithelial cells. J Biomed Opt 2006; 11(6): 064012, https://doi. org/10.1117/1.2401149.

54. Natal R. de A., Pelegati V.B., Bondarik C., Mendonça G.R., Derchain S.F., Lima C.P., Cesar C.L., Sarian L.O., Vassalloet J. Increased metabolic activity detected by FLIM in human breast cancer cells with desmoplastic reaction: a pilot study. Proc. SPIE 9536, Advanced Microscopy Techniques IV; and Neurophotonics II, 95360L (July 14, 2015), https://doi.org/10.1117/12.2183442.

55. Quinn K.P., Sridharan G.V., Hayden R.S., Kaplan D.L., Lee K., Georgakoudi I. Quantitative metabolic imaging using endogenous fluorescence to detect stem cell differentiation. Sci Rep 2013; 3: 3432, https://doi.org/10.1038/srep03432.

56. Zhang Z., Blessington D., Li H., Busch T.M., Glickson J., Luo Q., Chance B., Zheng G. Redox ratio of mitochondria as an indicator for the response of photodynamic therapy. J Biomed Opt 2004; 9(4): 772-778, https://doi. org/10.1117/1.1760759.

57. Druzhkova I.N., Shirmanova M.V., Lukina M.M., Dudenkova V.V., Mishina N.M., Zagaynova E.V. The metabolic interaction of cancer cells and fibroblasts - coupling between $\mathrm{NAD}(\mathrm{P}) \mathrm{H}$ and $\mathrm{FAD}$, intracellular $\mathrm{pH}$ and hydrogen peroxide. Cell Cycle 2016; 15(9): 1257-1266, https://doi.org/10.1080/15 384101.2016.1160974.

58. Skala M., Ramanujam N. Multiphoton redox ratio imaging for metabolic monitoring in vivo. Methods $\mathrm{Mol}$ Biol 2010; 594: 155-162, https://doi.org/10.1007/978-1-60761-411111 .
59. Skala M.C., Fontanella A., Lan L., Izatt J.A., Dewhirst M.W. Longitudinal optical imaging of tumor metabolism and hemodynamics. J Biomed Opt 2010; 15(1): 011112, https://doi.org/10.1117/1.3285584.

60. Skala M.C., Riching K.M., Gendron-Fitzpatrick A., Eickhoff J., Eliceiri K.W., White J.G., Ramanujam N. In vivo multiphoton microscopy of $\mathrm{NADH}$ and $\mathrm{FAD}$ redox states, fluorescence lifetimes, and cellular morphology in precancerous epithelia. Proc Natl Acad Sci USA 2007; 104(49): 19494-19499, https://doi.org/10.1073/pnas.0708425104.

61. Cannon T.M., Shah A.T., Walsh A.J., Skala M.C. Highthroughput measurements of the optical redox ratio using a commercial microplate reader. J Biomed Opt 2015; 20(1): 010503, https://doi.org/10.1117/1.jbo.20.1.010503.

62. Ostrander J.H., McMahon C.M., Lem S., Millon S.R., Brown J.Q., Seewaldt V.L., Ramanujam N. Optical redox ratio differentiates breast cancer cell lines based on estrogen receptor status. Cancer Res 2010; 70(11): 4759-4766, https:// doi.org/10.1158/0008-5472.can-09-2572.

63. Staniszewski K., Audi S.H., Sepehr R., Jacobs E.R., Ranji M. Surface fluorescence studies of tissue mitochondrial redox state in isolated perfused rat lungs. Ann Biomed Eng 2013; 41(4): 827-836, https://doi.org/10.1007/s10439-0120716-z.

64. Sepehr R., Staniszewski K., Maleki S., Jacobs E.R., Audi S., Ranji M. Optical imaging of tissue mitochondrial redox state in intact rat lungs in two models of pulmonary oxidative stress. J Biomed Opt 2012; 17(4): 046010, https://doi. org/10.1117/1.JBO.17.4.046010.

65. Currie E., Schulze A., Zechner R., Walther T.C., Farese R.V. Jr. Cellular fatty acid metabolism and cancer. Cell Metab 2013; 18(2): 153-161, https://doi.org/10.1016/j. cmet.2013.05.017.

66. Fox C.J., Hammerman P.S., Thompson C.B. Fuel feeds function: energy metabolism and the T-cell response. Nat Rev Immunol 2005; 5(11): 844-852, https://doi.org/10.1038/ nri1710.

67. Chance B. Optical method. Annu Rev Biophys Biophys Chem 1991; 20(1): 1-30, https://doi.org/10.1146/annurev. bb.20.060191.000245.

68. Palmer S., Litvinova K., Rafailov E.U., Nabi G. Detection of urinary bladder cancer cells using redox ratio and double excitation wavelengths autofluorescence. Biomed Opt Express 2015; 6(3): 977-986, https://doi.org/10.1364/ BOE.6.000977.

69. Cannon T.M., Shah A.T., Skala M.C. Validation and characterization of optical redox ratio measurements with a microplate reader in breast cancer cells. Proc. SPIE 9303, Photonic Therapeutics and Diagnostics XI, 93032S (February 26, 2015), https://doi.org/10.1117/12.2077941.

70. Hou J., Wright H.J., Chan N., Tran R., Razorenova O.V., Potma E.O., Tromberg B.J. Correlating two-photon excited fluorescence imaging of breast cancer cellular redox state with seahorse flux analysis of normalized cellular oxygen consumption. J Biomed Opt 2016; 21(6): 60503, https://doi. org/10.1117/1.JBO.21.6.060503.

71. Walsh A., Cook R.S., Rexer B., Arteaga C.L., Skala M.C. Optical imaging of metabolism in HER2 overexpressing breast cancer cells. Biomed Opt Express 2012; 3(1): 75-85, https:// doi.org/10.1364/boe.3.000075.

72. Walsh A.J., Cook R.S., Manning H.C., Hicks D.J., Lafontant A., Arteaga C.L., Skala M.C. Optical metabolic imaging identifies glycolytic levels, sub-types and early 
treatment response in breast cancer. Cancer Res 2013; 73(20): 6164-6174, https://doi.org/10.1158/0008-5472.can-13-0527.

73. Levitt J.M., McLaughlin-Drubin M.E., Münger K., Georgakoudi I. Automated biochemical, morphological, and organizational assessment of precancerous changes from endogenous two-photon fluorescence images. PLoS One 2011; 6(9): e24765, https://doi.org/10.1371/journal. pone. 0024765 .

74. Shah A.T., Demory Beckler M., Walsh A.J., Jones W.P., Pohlmann P.R., Skala M.C. Optical metabolic imaging of treatment response in human head and neck squamous cell carcinoma. PLoS One 2014; 9(3): e90746, https://doi. org/10.1371/journal.pone.0090746.

75. Kirkpatrick N.D., Zou C., Brewer M.A., Brands W.R., Drezek R.A., Utzinger U. Endogenous fluorescence spectroscopy of cell suspensions for chemopreventive drug monitoring. Photochem Photobiol 2005; 81(1): 125-134, https://doi.org/10.1562/2004-08-09-ra-267.1.

76. Gurushankar K., Nazeer S.S., Jayasree R.S., Krishnakumar N. Evaluation of antitumor activity of hesperetin-loaded nanoparticles against dmba-induced oral carcinogenesis based on tissue autofluorescence spectroscopy and multivariate analysis. J Fluoresc 2015; 25(4): 931-939, https://doi.org/10.1007/s10895-015-1575-4.

77. Gohulkumar M., Nazeer S.S., Jayasree R.S., Gurushankar K., Krishnakumar N. Monitoring the metabolic response to nanoencapsulated silibinin treatment in DMBAinduced oral carcinogenesis using endogenous fluorescence. Anal Methods 2014; 6(24): 9744-9753, https://doi.org/10.1039/ c4ay01877j.

78. Xu H.N., Nioka S., Glickson J.D., Chance B., Li L.Z. Quantitative mitochondrial redox imaging of breast cancer metastatic potential. J Biomed Opt 2010; 15(3): 036010, https://doi.org/10.1117/1.3431714.

79. Shah A.T., Diggins K.E., Walsh A.J., Irish J.M., Skala M.C. In vivo autofluorescence imaging of tumor heterogeneity in response to treatment. Neoplasia 2015; 17(12): 862-870, https://doi.org/10.1016/j.neo.2015.11.006.

80. Zhang M., Zhang Z., Blessington D., Li H., Busch T.M., Madrak V., Miles J., Chance B., Glickson J.D., Zheng G. Pyropheophorbide 2-deoxyglucosamide: a new photosensitizer targeting glucose transporters. Bioconjug Chem 2003; 14(4): 709-714, https://doi.org/10.1021/bc034038n.

81. Shah A.T., Skala M.C. Ex vivo label-free microscopy of head and neck cancer patient tissues. Proc. SPIE 9329, Multiphoton Microscopy in the Biomedical Sciences $\mathrm{XV}$, 93292B (March 5, 2015), https://doi.org/10.1117/12.2075583.

82. Ramanujam N., Richards-Kortum R., Thomsen S., Mahadevan-Jansen A., Follen M., Chance B. Low temperature fluorescence imaging of freeze-trapped human cervical tissues. Opt Express 2001; 8(6): 335-343, https://doi.org/10.1364/ oe.8.000335.

83. Liu Q., Grant G., Li J., Zhang Y., Hu F., Li S., Wilson C., Chen K., Bigner D., Vo-Dinh T. Compact point-detection fluorescence spectroscopy system for quantifying intrinsic fluorescence redox ratio in brain cancer diagnostics. $J$ Biomed Opt 2011; 16(3): 037004, https://doi.org/10.1117/1.3558840.

84. Georgakoudi I., Jacobson B.C., Müller M.G., Sheets E.E., Badizadegan K., Carr-Locke D.L., Crum C.P., Boone C.W., Dasari R.R., Van Dam J., Feld M.S. NAD(P) $\mathrm{H}$ and collagen as in vivo quantitative fluorescent biomarkers of epithelial precancerous changes. Cancer Res 2002; 62(3): 682-687.
85. Müller M.G., Valdez T.A., Georgakoudi I., Backman V., Fuentes C., Kabani S., Laver N., Wang Z., Boone C.W., Dasari R.R., Shapshay S.M., Feld M.S. Spectroscopic detection and evaluation of morphologic and biochemical changes in early human oral carcinoma. Cancer 2003; 97(7): 1681-1692, https://doi.org/10.1002/cncr.11255.

86. Yu Q., Heikal A.A. Two-photon autofluorescence dynamics imaging reveals sensitivity of intracellular NADH concentration and conformation to cell physiology at the singlecell level. J Photochem Photobiol B 2009; 95(1): 46-57, https:// doi.org/10.1016/j.jphotobiol.2008.12.010.

87. Tregidgo C., Levitt J.A., Suhling K. Effect of refractive index on the fluorescence lifetime of green fluorescent protein. J Biomed Opt 2008; 13(3): 031218, https://doi. org/10.1117/1.2937212.

88. van Manen H.J., Verkuijlen P., Wittendorp P., Subramaniam V., van den Berg T.K., Roos D., Otto C. Refractive index sensing of green fluorescent proteins in living cells using fluorescence lifetime imaging microscopy. Biophys J 2008; 94(8): L67-L69, https://doi.org/10.1529/ biophysj.107.127837.

89. Lakowicz J.R., Szmacinski H., Nowaczyk K., Johnson M.L. Fluorescence lifetime imaging of free and protein-bound NADH. Proc Natl Acad Sci USA 1992; 89(4): 1271-1275, https://doi.org/10.1073/pnas.89.4.1271.

90. Duncan R.R. Fluorescence lifetime imaging microscopy (FLIM) to quantify protein-protein interactions inside cells. Biochem Soc Trans 2006; 34(Pt 5): 679-682, https://doi. org/10.1042/bst0340679.

91. Elson D., Webb S., Siegel J., Suhling K., Davis D., Lever J., Phillips D., Wallace A., French P. Biomedical applications of fluorescence lifetime imaging. Opt Photon News 2002; 13(11): 26-32, https://doi.org/10.1364/ opn.13.11.000026.

92. Campos-Delgado D.U., Navarro O.G., ArceSantana E.R., Walsh A.J., Skala M.C., Jo J.A. Deconvolution of fluorescence lifetime imaging microscopy by a library of exponentials. Opt Express 2015; 23(18): 23748-23767, https:// doi.org/10.1364/oe.23.023748.

93. Becker W. Fluorescence lifetime imaging - techniques and applications. J Microsc 2012; 247(2): 119-136, https://doi. org/10.1111/j.1365-2818.2012.03618.x.

94. Becker W., Bergmann A., Hink M.A., Konig K., Benndorf K., Biskup C. Fluorescence lifetime imaging by timecorrelated single-photon counting. Microsc Res Tech 2004; 63(1): 58-66, https://doi.org/10.1002/jemt.10421.

95. Skala M.C., Riching K.M., Bird D.K., GendronFitzpatrick A., Eickhoff J., Eliceiri K.W., Keely P.J., Ramanujam N. In vivo multiphoton fluorescence lifetime imaging of protein-bound and free nadh in normal and precancerous epithelia. J Biomed Opt 2007; 12(2): 024014, https://doi.org/10.1117/1.2717503.

96. Kantelhardt S.R., Kalasauskas D., Konig K., Kim E., Weinigel M., Uchugonova A., Giese A. In vivo multiphoton tomography and fluorescence lifetime imaging of human brain tumor tissue. J Neurooncol 2016; 127(3): 473-482, https://doi. org/10.1007/s11060-016-2062-8.

97. Seidenari S., Arginelli F., Dunsby C., French P.M., Konig K., Magnoni C., Talbot C., Ponti G. Multiphoton laser tomography and fluorescence lifetime imaging of melanoma: morphologic features and quantitative data for sensitive and specific non-invasive diagnostics. PLOS ONE 2013; 8(7): e70682, https://doi.org/10.1371/journal.pone.0070682. 
98. Ruck A., Hauser C., Mosch S., Kalinina S. Spectrally resolved fluorescence lifetime imaging to investigate cell metabolism in malignant and nonmalignant oral mucosa cells. J Biomed Opt 2014; 19(9): 096005, https://doi.org/10.1117/1. jbo.19.9.096005.

99. Ramanujan V.K., Zhang J.H., Biener E., Herman B. Multiphoton fluorescence lifetime contrast in deep tissue imaging: prospects in redox imaging and disease diagnosis. J Biomed Opt 2005; 10(5): 051407, https://doi. org/10.1117/1.2098753.

100. Vergen J., Hecht C., Zholudeva L.V., Marquardt M.M., Hallworth R., Nichols M.G. Metabolic imaging using twophoton excited NADH intensity and fluorescence lifetime imaging. Microsc Microanal 2012; 18(4): 761-770, https://doi. org/10.1017/S1431927612000529.

101. Bird D.K., Yan L., Vrotsos K.M., Eliceiri K.W., Vaughan E.M., Keely P.J., White J.G., Ramanujam N. Metabolic mapping of MCF10A human breast cells via multiphoton fluorescence lifetime imaging of the coenzyme NADH. Cancer Res 2005; 65(19): 8766-8773, https://doi. org/10.1158/0008-5472.can-04-3922.

102. Islam M.S., Honma M., Nakabayashi T., Kinjo M., Ohta N. pH dependence of the fluorescence lifetime of FAD in solution and in cells. Int J Mol Sci 2013; 14(1): 1952-1963, https://doi.org/10.3390/ijms14011952.

103. Horilova J., Cunderlikova B., Marcek Chorvatova A. Time- and spectrally resolved characteristics of flavin fluorescence in U87MG cancer cells in culture. J Biomed Opt 2015; 20(5): 051017, https://doi.org/10.1117/1.jbo.20.5.051017.

104. Fatakdawala H., Poti S., Zhou F., Sun Y., Bec J., Liu J., Yankelevich D.R., Tinling S.P., Gandour-Edwards R.F., Farwell D.G., Marcu L. Multimodal in vivo imaging of oral cancer using fluorescence lifetime, photoacoustic and ultrasound techniques. Biomed Opt Express 2013; 4(9): 17241741, https://doi.org/10.1364/boe.4.001724.

105. Adur J., Pelegati V.B., de Thomaz A.A., Baratti M.O., Almeida D.B., Andrade L.A., Bottcher-Luiz F., Carvalho H.F., Cesar C.L. Optical biomarkers of serous and mucinous human ovarian tumor assessed with nonlinear optics microscopies. PLoS ONE 2012; 7(10): e47007, https://doi.org/10.1371/ journal.pone.0047007.

106. Galletly N.P., McGinty J., Dunsby C., Teixeira F., Requejo-Isidro J., Munro I., Elson D.S., Neil M.A., Chu A.C., French P.M., Stamp G.W. Fluorescence lifetime imaging distinguishes basal cell carcinoma from surrounding uninvolved skin. Br J Dermatol 2008; 159(1): 152-161, https:// doi.org/10.1111/j.1365-2133.2008.08577.x.

107. McGinty J., Galletly N.P., Dunsby C., Munro I., Elson D.S., Requejo-Isidro J., Cohen P., Ahmad R., Forsyth A., Thillainayagam A.V., Neil M.A.A., French P.M.W., Stamp G.W. Wide-field fluorescence lifetime imaging of cancer. Biomed Opt Express 2010; 1(2): 627-640, https://doi.org/10.1364/ boe.1.000627.

108. Sun Y., Hatami N., Yee M., Phipps J., Elson D.S., Gorin F., Schrot R.J., Marcu L. Fluorescence lifetime imaging microscopy for brain tumor image-guided surgery. J Biomed Opt 2010; 15(5): 056022, https://doi.org/10.1117/1.3486612.

109. Sun Y., Phipps J.E., Meier J., Hatami N., Poirier B., Elson D.S., Farwell D.G., Marcu L. Endoscopic fluorescence lifetime imaging for in vivo intraoperative diagnosis of oral carcinoma. Microscopy and Microanalysis 2013; 19(4): 791798, https://doi.org/10.1017/s1431927613001530.

110. Butte P.V., Mamelak A.N., Nuno M., Bannykh S.I., Black K.L., Marcu L. Fluorescence lifetime spectroscopy for guided therapy of brain tumors. Neuroimage 2011; 54(Suppl 1): S125-S135, https://doi.org/10.1016/j.neuroimage.2010.11.001. 